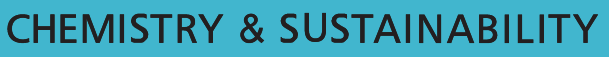 CHEMSUSCHEM
}

\author{
ENERGY \& MATERIALS
}

\section{Accepted Article}

Title: Novel perovskite materials for thermal water splitting at moderate temperature

Authors: M. Teresa Azcondo, María orfila, Javier Marugan, Raul Sanz, Alvaro Muñoz-Noval, Eduardo Salas, Clemens Ritter, Flaviano Garcia-Alvarado, and Ulises Amador

This manuscript has been accepted after peer review and appears as an Accepted Article online prior to editing, proofing, and formal publication of the final Version of Record (VoR). This work is currently citable by using the Digital Object Identifier (DOI) given below. The VoR will be published online in Early View as soon as possible and may be different to this Accepted Article as a result of editing. Readers should obtain the VoR from the journal website shown below when it is published to ensure accuracy of information. The authors are responsible for the content of this Accepted Article.

To be cited as: ChemSusChem 10.1002/cssc. 201901484

Link to VoR: http://dx.doi.org/10.1002/cssc.201901484 


\title{
Novel perovskite materials for thermal water splitting at moderate temperature
}

\author{
M. Teresa Azcondo, ${ }^{[a],}$ María Orfila, ${ }^{[b],{ }^{*}}$ Javier Marugán, ${ }^{[b]}$ Raúl Sanz, ${ }^{[b]}$ Alvaro Muñoz-Noval, ${ }^{[c]}$ \\ Eduardo Salas-Colera, ${ }^{[\mathrm{d}]}$ Clemens Ritter, ${ }^{[\mathrm{e}]}$ Flaviano García-Alvarado, ${ }^{[\mathrm{a}]}$ and Ulises Amador ${ }^{[\mathrm{a}]}$
}

\begin{abstract}
Materials with formula $\mathrm{Sr}_{2} \mathrm{CoNb}_{1-x} \mathrm{Ti}_{x} \mathrm{O}_{6-\delta}(\mathrm{x}=1.00,0.70)$ present a cubic perovskite-like structure. They are easily and reversibly reduced (in $\mathrm{N}_{2}$ or $\mathrm{Ar}$ ) and re-oxidized (in air) upon heating. Oxidation by water, (wet $\mathrm{N}_{2}$ ), involving splitting of water at a temperature as low as $700^{\circ} \mathrm{C}$, produces hydrogen. Both compounds display outstanding $\mathrm{H}_{2}$ production in the first thermochemical cycle, the $\mathrm{Sr}_{2} \mathrm{CoNb}_{0.30} \mathrm{Ti}_{0.70} \mathrm{O}_{6-\delta}$ material retaining its outstanding performance upon cycling, whereas the hydrogen yield of the $x=1$ oxide shows a continuous decay. The retention of the materials' ability to promote water splitting correlates with their structural, chemical and redox reversibility upon cycling. On reduction/oxidation, Co ions reversibly change their oxidation state to compensate the release/recovering of oxygen in both compounds. However, in $\mathrm{Sr}_{2} \mathrm{CoTiO}_{6-\delta}$ two phases with different oxygen contents segregate, whereas in $\mathrm{Sr}_{2} \mathrm{CoNb}_{0.30} \mathrm{Ti}_{0.70} \mathrm{O}_{6-\delta}$ this effect is no evident. Therefore, this latter material displays a hydrogen production as high as 410 $\mu \mathrm{molH}{ }_{2} / \mathrm{g}_{\text {perovskite }}$ after 8 thermochemical cycles at $700^{\circ} \mathrm{C}$, among the highest ever reported, making this perovskite a promising candidate for thermo-solar water splitting in real devices.
\end{abstract}

\section{Introduction}

Global energy consumption grows every year, and more than $85 \%$ of the total energy demand is still covered by fossil fuels such as coal, oil and natural gas. This dependence has important economic and environmental implications. From an economic point of view, it is noteworthy that the production is located in certain areas of the world, which results in volatile and high prices governed by political factors. In addition, due to the absence of other viable alternatives, the depletion of oil reserves will result in a progressive rise of the prices that may jeopardize the global economic development. On the environmental side, the combustion of fossil fuels is the main cause of the greenhouse gases emissions $\left(\mathrm{CO}_{2}\right)$, responsible for the global warming effect. ${ }^{[1]}$ The present situation is unsustainable in the

[a] Prof. M. Teresa Azcondo, Prof. Flaviano García-Alvarado, Prof. Ulises Amador

Universidad San Pablo-CEU, CEU Universities, Facultad de Farmacia, Departamento de Química y Bioquímica, Urbanización Montepríncipe, Boadilla del Monte, E-28668, Madrid, Spain E-mail: azcondo@ceu.es

[b] Dr. María Orfila, Prof. Raúl Sanz Martín, Prof. Javier Marugán Departamento de Tecnología Química y Ambiental, Escuela Superior de Ciencias Experimentales y Tecnología, Universidad Rey Juan Carlos, Móstoles, E-28933, Madrid, Spain. E-mail: maria.orfila@urjc.es

[c] Dr. Alvaro Muñoz-Noval

Departamento de Física de Materiales, Facultad de Físicas, Universidad. Complutense, E-28040 Madrid, Spain.

[d] Dr. Eduardo Salas Colera

SpLine Spanish CRG Beamline, ESRF, 6 Rue J. Horowitz, Grenoble, Isere/Rhone-Alpes, 38042, France.

[e] Dr. Clemens Ritter Institut Laue-Langevin, BP 156-38042 Grenoble Cedex 9, France medium term, so the development of fossil-fuel free economies and societies is a major challenge for the XXl's century world.

Many alternative energy production and storage technologies to take advantage of the abundant albeit intermittent renewable energies have been developed. ${ }^{[2]}$ In this context, hydrogen appears as a very promising energy vector, especially when the energy required for its production comes from the Sun as solar radiation, which is one of the primary sources of energy on Earth. $^{[3]}$ The cleanest and most direct method to obtain hydrogen from renewable sources is the direct splitting of water using solar thermal energy, according to eq (1):

$$
\mathrm{H}_{2} \mathrm{O} \stackrel{Q}{\rightarrow} \mathrm{H}_{2}+\frac{1}{2} \mathrm{O}_{2}
$$

However, the required temperatures for this reaction to be spontaneous are above $4250^{\circ} \mathrm{C},{ }^{[4]}$ far over the maximum temperatures achievable in modern solar concentrating systems (ca. $2700^{\circ} \mathrm{C}$ ) ${ }^{[5]}$ Additionally, there are other problems associated to this technology such as the huge radiation losses, which are proportional to the fourth power of the absolute temperature, and the need to separate hydrogen and oxygen to avoid explosive mixtures at lower temperatures. ${ }^{[6]}$ As an alternative, water splitting by solar-driven thermochemical cycles represents a promising technology. Thermochemical cycles involve two or more endo- and exothermic reactions with the overall process resulting in the splitting of water in $1 / 2 \mathrm{~mol}$ of $\mathrm{O}_{2}$ and $1 \mathrm{~mol}$ of $\mathrm{H}_{2}$ ${ }^{[7]}$ but with lower energy (temperature) requirements. Hydrogen and oxygen are produced at different steps eliminating thus the need to be separated. ${ }^{[8]}$

Of the more of 200 thermochemical cycles producing hydrogen reported in literature, those based on metal oxides and twosteps are the most attractive for coupling with solar concentrated energy ${ }^{\left[{ }^{9]}\right.}$ These cycles consist of a first step in which the metal oxide is reduced at high temperature releasing $\mathrm{O}_{2}$ (eq (2)), and a second step in which the reduced metal oxide reacts with $\mathrm{H}_{2} \mathrm{O}$ to produce $\mathrm{H}_{2}$ and regenerate the starting material (eq (3)). ${ }^{[10]}$

$$
\begin{aligned}
& \mathrm{MeO}_{y} \rightarrow \mathrm{MeO}_{y-x}+\frac{x}{2} \mathrm{O}_{2} \\
& \mathrm{MeO}_{y-x}+x \mathrm{H}_{2} \mathrm{O} \rightarrow \mathrm{MeO}_{y}+x \mathrm{H}_{2}
\end{aligned}
$$

Despite the apparent simplicity of the process, the temperature required for the reduction of the metal oxides commonly studied for this application is very high $\left(\mathrm{MgO}\right.$ and $\mathrm{Fe}_{2} \mathrm{O}_{3} \sim 3400^{\circ} \mathrm{C}, \mathrm{TiO}_{2}$ $\left.\sim 3700{ }^{\circ} \mathrm{C}, \mathrm{CeO}_{2} \sim 2000{ }^{\circ} \mathrm{C}\right),{ }^{[11]}$ the stoichiometric oxides which would be reduced at lower temperatures not being able to produce $\mathrm{H}_{2}$ by a two-step thermochemical cycle using water as 
oxidizing agent. ${ }^{[8]}$ As an alternative, non-stoichiometric oxides have been proposed as potential materials for solar thermal hydrogen production at lower operational temperatures. ${ }^{[12]}$ These oxides display advantageous properties such as a large degree of reduction at moderate temperatures, rapid oxidation and reduction kinetics, favorable oxidation thermodynamics and stability at high temperatures. ${ }^{[13]}$ In this context, perovskites oxides may stand as promising candidates for hydrogen production by thermochemical water splitting. ${ }^{[12 b, 12 c, 14]}$ The nonstoichiometric perovskite acts as a solid-state oxygen carrier which facilitates water reduction into hydrogen. ${ }^{[15]}$

Perovskites, with general formula $A B X_{3}$, represent a huge family of highly versatile materials, from both structural and chemical points of view. The structure accommodates a large variety of metal ions with variable oxidation states, and the anionic substructure tolerates considerable concentrations of vacancies. ${ }^{[16]}$ These features make it possible to tune the properties of many perovskites in a large extend. It is well known that a number of perovskite oxides present interesting applications as electrodes in several solid-state electrochemical devices. ${ }^{[17]}$ In particular, those perovskite oxides displaying both mixed ionic-electronic conductivity (MIEC), and high catalytic activity for oxygen reduction, are of considerable interest as air electrode (cathode) materials in solid oxide fuel cells (SOFC). ${ }^{[18]}$ MIEC is related to the presence of mobile oxygen vacancies and the ability to gain/loss oxygen under different oxygen partial pressures $\left(\mathrm{pO}_{2}\right)$, as metal ions present mixed oxidation states, this being also associated with catalytic properties. ${ }^{[12 b, 19]}$ On the other hand, many SOFC cathode materials are reversibly reduced and oxidized, as revealed by their electrochemical properties. ${ }^{[20]}$ Reversibility of reduction/oxidation and catalytic activity are highly desirable in a material to be used for water splitting. ${ }^{[12 b, 12 c]}$ Thus, a large number of materials studied as potential SOFC cathodes could be useful for hydrogen production. Besides, the material should not undergo phase transitions on heating/cooling cycles at different $\mathrm{pO}_{2}$ atmospheres to ensure durability and good long-term performances. ${ }^{[21]} A$ thermochemical cycle based on a perovskite material is schematized as follows: first, the perovskite is thermally reduced releasing oxygen (eq (4)) and second, the reduced perovskite reacts with water to produce hydrogen and regenerate the initial material (eq (5); Figure 1).

In recent papers we have studied the structure and microstructure ${ }^{[22]}$ as well as the performance as SOFC cathode ${ }^{[20 a]}$ of materials with compositions $\mathrm{Sr}_{2} \mathrm{CoNb}_{1-\mathrm{x}} \mathrm{Ti}_{x} \mathrm{O}_{6-\delta}(0 \leq$ $x \leq 1$ ) which fulfil all the requirements mentioned. Along the whole series, transport properties and catalytic activity vary with the titanium content. Increasing Ti-content from $x=0$ to $x=1$ induces both the oxidation of $\mathrm{Co}^{3+}$ into $\mathrm{Co}^{4+}$ (from $0 \%$ up to $40 \%$ ) and the generation of oxygen vacancies (from 6.0 to 5.7 oxygen atom/formula unit), resulting in improved performances as SOFC cathode. However, samples with high Ti-contents lose significant amounts of oxygen on heating, which is only partially retrieved on cooling. Lowering the $\mathrm{Ti} / \mathrm{Nb}$ ratio decreases the material's catalytic activity and the amount of released/retrieved oxygen as well; the less extensive the reduction/oxidation processes are, the more reversible they are expected to be. Besides, the material's microstructure may play a relevant role in reduction/oxidation since oxygen vacancies can be accommodated in the domain walls. ${ }^{[22]}$ Neither $\mathrm{Ti}^{4+}$ nor $\mathrm{Nb}^{5+}$ experience any oxidation/reduction processes; the couple $\mathrm{Co}^{4+} / \mathrm{Co}^{3+}$ is the sole responsible for the redox behavior of these materials. ${ }^{[20 \mathrm{a}]}$

$$
\begin{aligned}
& A_{1-x} A^{\prime}{ }_{x} \mathrm{BO}_{3-\delta} \rightarrow A_{1-x} A^{\prime}{ }_{x} \mathrm{BO}_{3-\delta-\alpha}+\frac{\alpha}{2} \mathrm{O}_{2} \\
& A_{1-x} A^{\prime}{ }_{x} \mathrm{BO}_{3-\delta-\alpha}+\mathrm{H}_{2} \mathrm{O} \rightarrow A_{1-x} A^{\prime}{ }_{x} \mathrm{BO}_{3-\delta}+\alpha H_{2}
\end{aligned}
$$

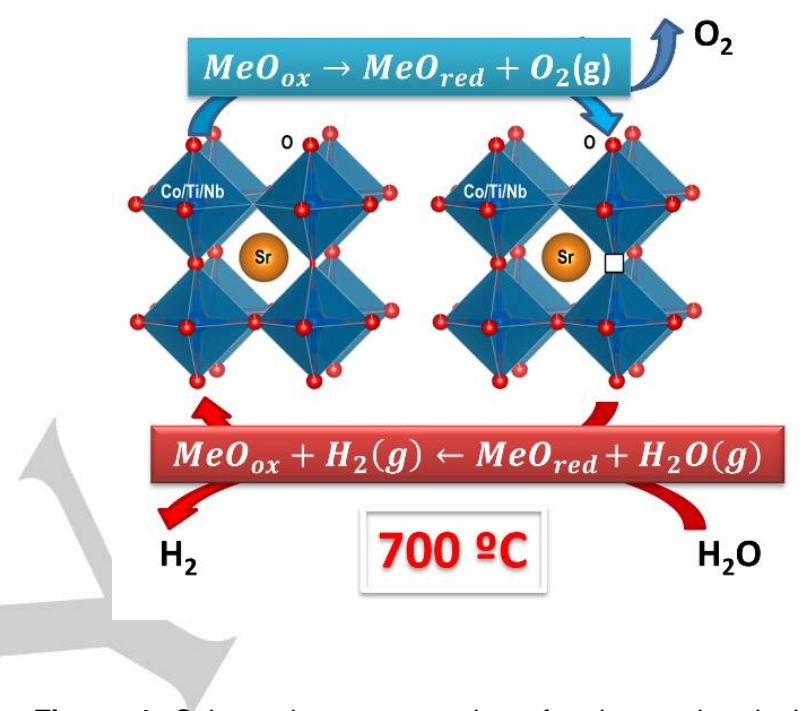

Figure 1. Schematic representation of a thermochemical cycle based on a cubic perovskite oxide of the $\mathrm{Sr}_{2} \mathrm{CoNb}_{1-\mathrm{x}} \mathrm{Ti}_{\mathrm{x}} \mathrm{O}_{6-\delta}(0 \leq \mathrm{x}$ $\leq 1)$ series; oxygen vacancies are denoted by $\square$.

Bearing in mind all the above results, oxides with $x=1.00$ and 0.70 were chosen to study their performance in thermal watersplitting. Among the entire series, for $\mathrm{Sr}_{2} \mathrm{CoNbTiO}_{6-\delta}$ a maximum $\mathrm{H}_{2}$ production is expected whereas the perovskite with $\mathrm{x}=0.70$ might represent a compromise between relatively high $\mathrm{H}_{2}$ yield and reversibility.

\section{Results and Discussion}

\section{Structure under reducing and oxidizing atmospheres}

Samples of compositions $\mathrm{Sr}_{2} \mathrm{CoNb}_{1-\mathrm{x}} \mathrm{Ti}_{\mathrm{x}} \mathrm{O}_{6-\delta}(\mathrm{x}=0.70,1.00)$ prepared in air are single-phase, as revealed by XRD. Both materials display at RT a simple cubic perovskite structure (Figure 1); Figure $\mathrm{S} 1$ shows the result of the fitting of XRD data to a cubic cell with $a=a_{p}\left(a_{p}\right.$ denotes the cell parameter of $a$ simple cubic perovskite) and space group (S.G.) Pm-3m (\#221). To determine the actual composition, especially the oxygen content, and the main structural features, joint fittings of XRD and NPD data have been performed. The final structural parameters are gathered in Table S1, whereas the graphic results of the fittings are depicted in Figure 2. No extra peaks 
are observed in the NPD patterns confirming that the samples are single-phase and the structure of both compounds is cubic. The metal composition of both materials corresponds to the nominal ones, within the experimental errors, whereas the resulting refined oxygen contents clearly indicate the presence of non-negligible amounts of oxygen vacancies. Despite this simple average structure, this family of materials presents a complex microstructure. ${ }^{[22]}$ Some of these oxides display performances as SOFC cathode that put them among the best materials for this application. ${ }^{[20 a]}$ Good electrochemical properties are related to proper catalytic activity (associated to cobalt) and to high electric conductivity, both electronic and ionic. The former is due to metals in mixed oxidation states, whereas the latter is associated to mobile oxygen vacancies. Both the metal oxidation states and the concentration of anionic vacancies may vary reversibly on heating/cooling under different atmospheres (i.e. $\mathrm{pO}_{2}$ ). ${ }^{[20 \mathrm{a}]}$ Thus, samples with $\mathrm{x}=0.70$ and 1.00 treated under $\mathrm{Ar}$ and pure oxygen have been studied by NPD. The final structural parameters of the resulting materials are collected in Table S1, whereas the graphic results of the data fittings are shown in Figure S2. The two oxides present some degree of anionic vacancies even after treatment in pure oxygen, the oxygen sub-stoichiometry being c.a. $2 \%$ and $4 \%$ for $x=0.70$ and $x=1.00$, respectively. As regards the results of the experiments under $\mathrm{Ar}$, compounds of the $\mathrm{Sr}_{2} \mathrm{CoNb}_{1-x} \mathrm{Ti}_{x} \mathrm{O}_{6-\delta}$ family seem to loose oxygen easily; ${ }^{[20 a]}$ when treated at low oxygen partial pressure in $\operatorname{Ar}$ flow $\left(\mathrm{pO}_{2} \approx 10^{-5}\right.$ atm.) the concentration of oxygen vacancies increases up to $11 \%$ for $x=0.70$ and $14 \%$ for $x=1.00$. As expected, the oxygen deficiency of samples prepared in air $\left(\mathrm{pO}_{2} \approx 0.20 \mathrm{~atm}\right.$.) is intermediate between those of the both ends conditions (Table S1). In any case, these materials seem to tolerate a wide range of oxygen deficiency since no decomposition products are detected in the NPD patterns (Figure S2).

The most relevant structural features related with the oxidizing/reducing treatments are the aforementioned change in oxygen content, the unit cell contraction/expansion and the variation of the atomic thermal factors (mainly those of oxygen). Thus, upon reduction (oxygen loss) the most evident chargecompensating mechanism is the reduction of cobalt ions ${ }^{[20 a]}$, as will be discussed below, according to eq (6):

$$
2 \mathrm{Co}_{C o}^{x}+O_{O}^{x} \stackrel{\operatorname{Red}}{\stackrel{\leftrightarrow}{\leftrightarrow} 2 C o_{C o}^{\prime}+V_{O}^{* \bullet}+\frac{1}{2} O_{2}(g)}
$$

The assignment of a definite radius to cobalt ions is not feasible due to their multiple spin states. Thus, the quantitative correlation of the unit cell size with the cobalt oxidation state cannot be directly established; ${ }^{23]}$ however, the higher the oxidation state is, the smaller the ionic size would be. ${ }^{[24]}$ Thus, the cell variations upon treatments under $\mathrm{O}_{2}$ and $\mathrm{Ar}$ streams (contraction and expansion, respectively) are associated to the changes in the cationic oxidation states (oxidation and reduction, respectively). Reduction and oxidation of the title materials are highly reversible processes and can be properly described by eq (6). Finally, the thermal factors' values increase as the concentration of oxygen vacancies does; this is most likely a signature of local disorder (not dynamical vibrations), mainly associated to oxygen ions since this family of oxides presents a complex microstructure ${ }^{[22]}$ where vacancies can be accommodated.
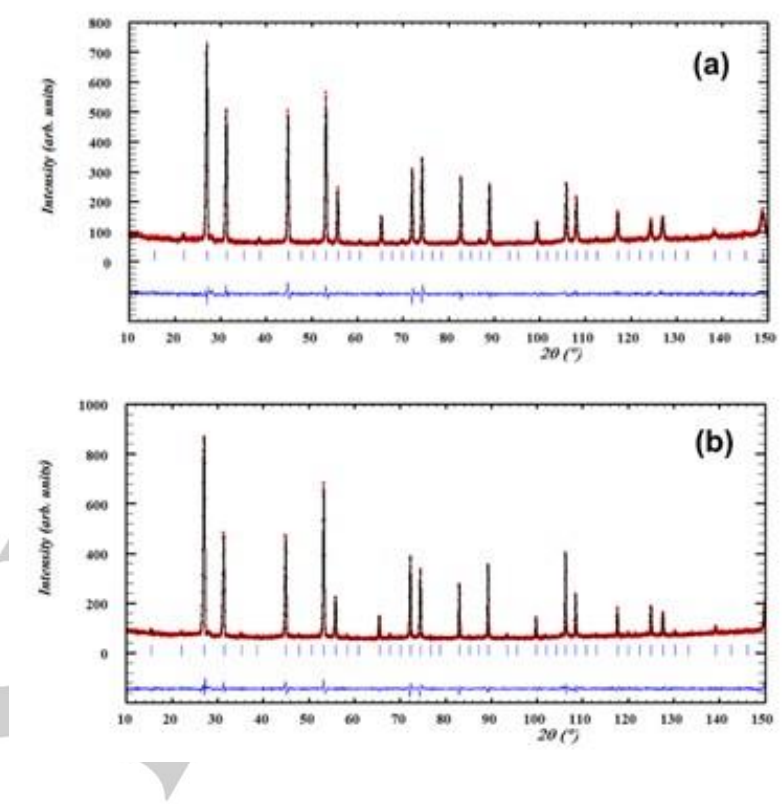

Figure 2. Experimental (red circles) and calculated (black continuous line) RT NPD patterns (and their difference, blue line at the bottom) for as-prepared (in air) oxides $\mathrm{Sr}_{2} \mathrm{CoNb}_{1-\mathrm{x}} \mathrm{Ti}_{\mathrm{x}} \mathrm{O}_{6-\delta}(\mathrm{a}) \mathrm{x}=0.70$ and (b) $\mathrm{x}=1.00$. Vertical bars indicate the positions of the Bragg peaks of the phases pre-sent in the sample.

\section{Reversibility of the reduction-oxidation processes}

As stated above, $\mathrm{Sr}_{2} \mathrm{CoNb}_{1-\mathrm{x}} \mathrm{Ti}_{\mathrm{x}} \mathrm{O}_{6-\delta}(\mathrm{x}=0.70,1.00)$ oxides can be reduced and oxidized reversibly according to eq (6). These reactions imply the release of oxygen during the thermal reduction step and the subsequent up-take of oxygen during the oxidation. The concomitant mass variations during four consecutive heating/cooling cycles are shown in Figure 3. Each cycle consists of two steps: heating from RT to $1000{ }^{\circ} \mathrm{C}$ under $\mathrm{N}_{2}$ flow to reduce the materials through oxygen loss (reverse reaction of the chemical equilibrium given by eq (6)), and then cooling down to RT under an air gas stream to re-oxidize the sample (direct reaction of eq (6)). Both, oxidation and reduction processes are reversible involving similar weight changes for the two oxides: $0.76 \%$ for $x=0.70$ and $0.82 \%$ for $x=1.00$. These are relatively high mass variations when compared to those of other perovskites materials candidates for thermal water splitting, such as $\mathrm{La}_{0.65} \mathrm{Sr}_{0.35} \mathrm{MnO}_{3 \pm \delta}, \mathrm{La}_{0.80} \mathrm{Sr}_{0.20} \mathrm{CoO}_{3 \pm \delta}$ and $\mathrm{La}_{0.60} \mathrm{Sr}_{0.40} \mathrm{FeO}_{3 \pm \delta}$ whose mass losses in the first cycle are $0.1 \%, 0.31 \%$ and $0.56 \%$, respectively. ${ }^{[14 c]}$ 

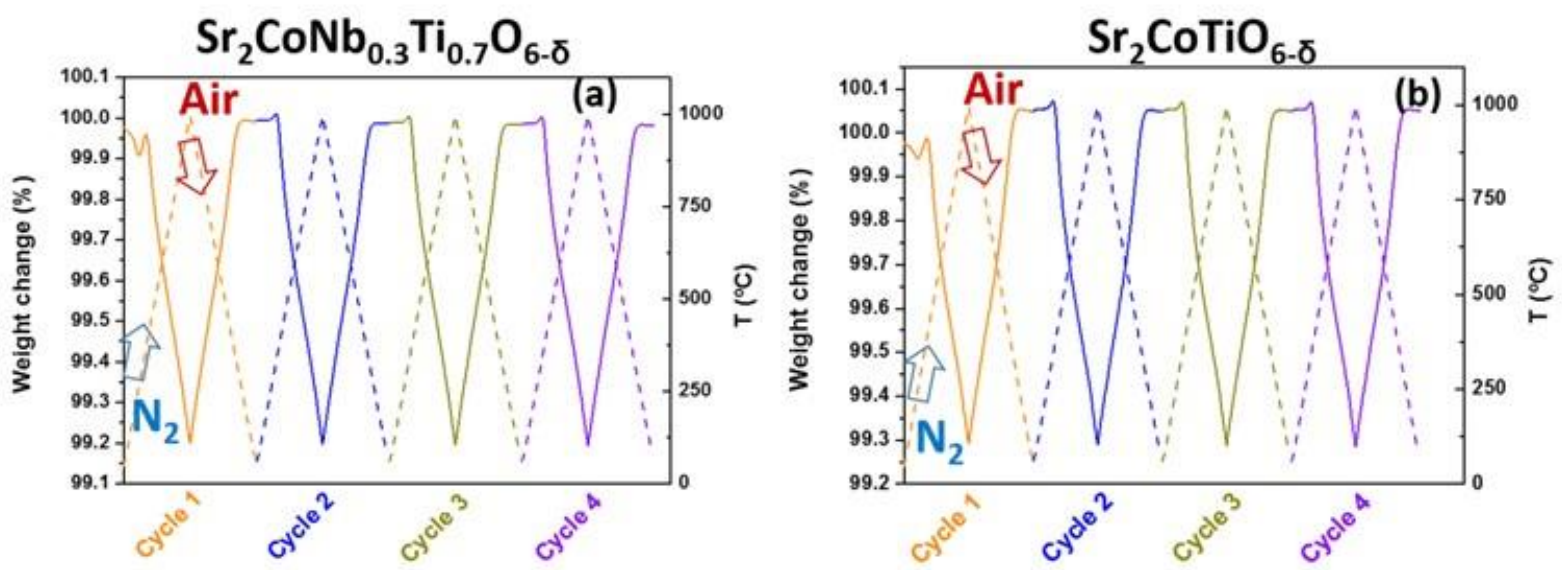

Figure 3. Reversible weight changes observed during four consecutive heating-cooling cycles of oxides $\mathrm{Sr}_{2} \mathrm{CoNb}_{1-\mathrm{x}} \mathrm{Ti}_{\mathrm{x}} \mathrm{O}_{6-\bar{\delta}} ;(\mathrm{a}) \mathrm{x}=0.70$ and $(\mathrm{b}) \mathrm{x}=1.00$. Heating under flowing pure $\mathrm{N}_{2}\left(\mathrm{pO} 2 \approx 10^{-5} \mathrm{~atm}\right.$.) and cooling under air $\left(\mathrm{pO}_{2} \approx 0.20 \mathrm{~atm}\right.$.).

The two former show poor reversibility of the reduction-oxidation cycles, whereas the latter totally decomposes after the first reduction. ${ }^{[14 c]}$ From the application point of view, the temperature at which the mass loss/gain occurs is highly relevant, since the lower this temperature is, the lower the operational temperature would be. Lower working temperature is a clear advantage, since implies lower energy requirements to meet, being this a critical factor for a full scale application in real solar devices. The reduction of the title materials starts at a temperature as low as $350^{\circ} \mathrm{C}$ (Figure S3), whereas in state-of-the-art compounds for thermochemical cycles this temperature is much higher. ${ }^{[25]}$ Thus, $\mathrm{MgO}$ and $\mathrm{Fe}_{2} \mathrm{O}_{3}$ are reduced about $\sim 3400^{\circ} \mathrm{C}, \mathrm{TiO}_{2} \sim 3700^{\circ} \mathrm{C}$ and $\mathrm{CeO}_{2} \sim 2000{ }^{\circ} \mathrm{C},{ }^{[11]}$. Such high temperatures are due to the stability of the metal oxidation states $\left(\mathrm{Mg}^{2+}, \mathrm{Fe}^{3+}, \mathrm{Ti}^{4+}\right.$ and $\left.\mathrm{Ce}^{4+}\right)$ and/or the difficulty of the corresponding structures (rock-salt, corundum, rutile and fluorite, respectively) to tolerate oxygen sub-stoichiometry; in contrast to the perovskite structure which can accommodate large degrees of oxygen substoichiometry. ${ }^{[12 \mathrm{~b}, 12 \mathrm{c}, 16,21 \mathrm{a}]}$ For example, only about $2 \%$ of the oxygen sites in ceria can be actively used for splitting of water. ${ }^{[26]}$ The highest non-stoichiometry of ceria in a thermochemical cycle at the reduction step, typically at $1500 \circ \mathrm{C}$, is only about $3 \%$ at $p\left(\mathrm{O}_{2}\right)=10^{-8}$ atm. (well below the value reached under inner gas flow $\left(\mathrm{Ar}\right.$ or $\mathrm{N}_{2}$ ) for which $\mathrm{p}\left(\mathrm{O}_{2}\right)=10^{-5}$ atm). ${ }^{[26-27]}$ In the title perovskites treated at $900{ }^{\circ} \mathrm{C}$ in $\mathrm{Ar}$ the concentrations of oxygen vacancies, determined by NPD, are $11 \%$ and $14 \%$ for the $x=0.70$ and $x=1.00$ compounds, respectively. The high reversibility of the reduction/oxidation processes displayed by the title oxides, discussed above in terms of weight changes, is due to good structural stability and redox reversibility (see below). In fact, the samples used in the above-discussed TG analyses all retain their structure after thermal cycling and no evidence of decomposition is observed (Figure S4).

\section{Oxidation by water}

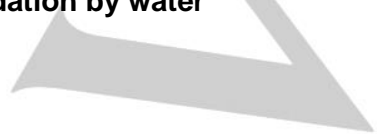

To produce hydrogen by water splitting, oxygen has to be replaced by water in the oxidation process shown in eq (6), as represented in eq (7):

$$
2 \mathrm{Co}_{\mathrm{Co}}^{\prime}+V_{o}^{\bullet \bullet}+\mathrm{H}_{2} \mathrm{O}(\mathrm{g}) \underset{\rightarrow}{\mathrm{Ox}} 2 \mathrm{Co}_{\mathrm{Co}}^{x}+\mathrm{O}_{O}^{x}+H_{2}(g)
$$

Thus, once reduced, treating the title oxides with water vapor may produce re-oxidation and hydrogen production. However, this process can compete with hydration, eq (8), without oxidation or hydrogen production:

$$
2 \mathrm{Co}_{\mathrm{Co}}^{\prime}+\mathrm{V}_{O}^{\bullet \bullet}+\mathrm{O}_{\mathrm{O}}^{x}+\mathrm{H}_{2} \mathrm{O}(\mathrm{g}) \stackrel{\mathrm{Hyd}}{\rightarrow} 2 \mathrm{Co}_{\mathrm{Co}}^{\prime}+2 \mathrm{OH}_{\mathrm{O}}^{\bullet}
$$

Processes (7) and (8) may occur to different extents. Therefore, it is crucial to elucidate which of them is actually predominant in the present materials. Weight changes do not provide conclusive evidence since both reactions imply mass gain on cooling from high temperature under wet atmosphere. Besides, hydrated samples will loss mass (water) on heating in dry conditions regardless the atmosphere being more or less oxidizing. Therefore, detection of hydrogen production in the oxidizing steps of the thermal cycles (by treatment under wet $\mathrm{N}_{2}$ stream) would provide more reliable information about which reaction is actually occurring. Up to eight complete cycles have been performed to test the materials' stability and performance. The cobalt oxidation state has been determined along the cycles, as well. This is a key piece of information, since the process given 
by eq (7) implies oxidation whereas that represented by eq (8) does not.

\section{Water splitting and hydrogen production}

Having assessed the reduction/oxidation ability of the title perovskites by TG analyses, the capacity for hydrogen production was evaluated as described in the experimental section on a high temperature tubular furnace coupled to a gas analyzer. The results obtained for both materials, $\mathrm{Sr}_{2} \mathrm{CoTiO}_{6-\delta}$ and $\mathrm{Sr}_{2} \mathrm{CoNb}_{0.30} \mathrm{Ti}_{0.70} \mathrm{O}_{6-\delta}$, along eight consecutive cycles are depicted in Figure 4. Although the degree of reduction estimated from the TGA data is slightly higher for $\mathrm{Sr}_{2} \mathrm{CoTiO}_{6-\delta}$, the actual $\mathrm{O}_{2}$ production obtained with both compounds is very similar. On the other hand, noticeable differences between the two materials are observed regarding hydrogen production. For $\mathrm{Sr}_{2} \mathrm{CoNb}_{1}$. ${ }_{x} \mathrm{Ti}_{\mathrm{x}} \mathrm{O}_{6-\delta}(\mathrm{x}=1.00) \mathrm{H}_{2}$ production remains almost constant up to the $5^{\text {th }}$ thermochemical cycle, after which it decreases progressively. This decay of activity upon cycling could be associated to sintering processes and segregation phenomena $^{[12 \mathrm{a}]}$ or to competition between processes described by eq (8) (hydration with water without oxidation) and eq (7) (hydrogen production). In contrast, $\mathrm{H}_{2}$ production by $\mathrm{Sr}_{2} \mathrm{CoNb}_{1}$. ${ }_{x} \mathrm{Ti}_{x} \mathrm{O}_{6-\delta}(\mathrm{x}=0.70)$ is almost constant along the 8 thermochemical cycles, showing a stable production of $410 \mu \mathrm{molH}_{2} / \mathrm{g}_{\text {perovskite. This }}$ $\mathrm{H}_{2}$ production level is among the highest ever reported: 398 $\mu \mathrm{molH}_{2} / \mathrm{g}$ for $\mathrm{La}_{1.6} \mathrm{Sr}_{0.4} \mathrm{MnO}_{3-\delta}$ working in the temperature range $800^{\circ} \mathrm{C}-1400^{\circ} \mathrm{C}^{[14 a]}$ and $600 \mu \mathrm{molH}_{2} / \mathrm{g}$ for $\mathrm{CoFe}_{2} \mathrm{O}_{4}$ on $\mathrm{Al}_{2} \mathrm{O}_{3}$ working at $1200{ }^{\circ} \mathrm{C} .{ }^{[28]}$ Noteworthy, the present results are obtained for as-prepared powders (micro-sized grains), with no textural or microstructural optimization (in contrast to what is reported in the literature $)^{[14 a, 28]}$ and, more importantly, working at the much lower temperature of $700^{\circ} \mathrm{C}$.

The two materials under study display very different kinetics of $\mathrm{H}_{2}$ production. In the case of $\mathrm{Sr}_{2} \mathrm{CoTiO}_{6-\delta}$ the $\mathrm{H}_{2}$ production rate decreases upon cycling from 4 to $0.2 \mu \mathrm{mol} / \mathrm{g}_{\text {perovskite }} \cdot \mathrm{min}$. On the contrary, the production rate of $\mathrm{Sr}_{2} \mathrm{CoNb}_{0.3} \mathrm{Ti}_{0.7} \mathrm{O}_{6-\delta}$ remains constant, with a value of $19.5 \pm 0.3 \mu \mathrm{mol} / \mathrm{g}_{\text {perovskite }} \cdot \min$ (Figures S5 and S6). This should is related with the different $\mathrm{H}_{2}$ production and cycling behavior of these perovskites.

The evolution of the $\mathrm{H}_{2} / \mathrm{O}_{2}$ production ratio confirms the different performance of these two materials. $\mathrm{Sr}_{2} \mathrm{CoTiO}_{6-\delta}$ clearly suffers from aging, since this ratio starts to decrease at the 4th cycle; for the first three cycles a constant value about 2.0 is observed which progressively diminishes down to 1.3 at the 8th cycle, suggesting that a significant part of the sample is no longer being re-oxidized by water. On the contrary, for the perovskite with $\mathrm{x}=0.70$ the volume of $\mathrm{H}_{2}$ produced is twice that of $\mathrm{O}_{2}$ up to the 8th cycle; therefore reduction/oxidation processes seem to be fully reversible. Worth to mention, an abrupt decrease of activity in both reduction and oxidation processes is observed in the 6th cycle. Since the material recovers and maintains its initial activity in successive cycles, the abnormal behavior in the 6th cycle would be likely due to an experimental failure.
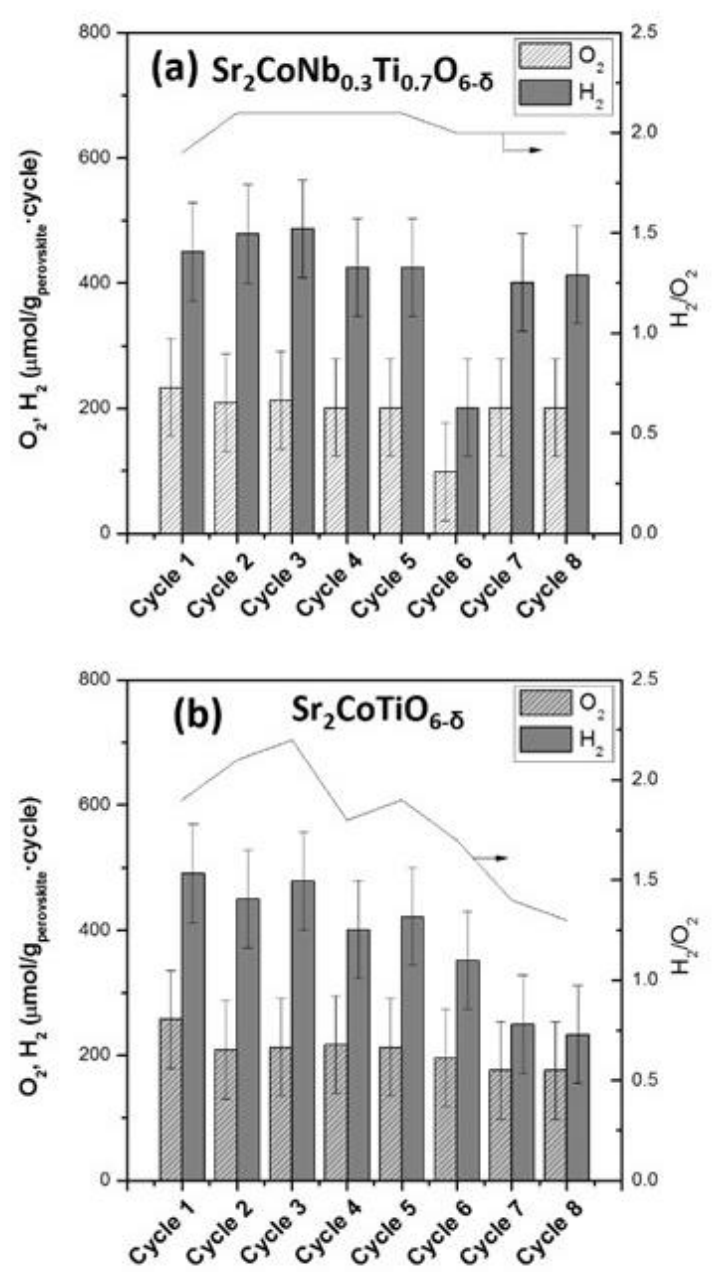

Figure 4. Oxygen and hydrogen production (in the reduction and oxidation steps, respectively) for the materials $\mathrm{Sr}_{2} \mathrm{CoNb}_{1-\mathrm{x}} \mathrm{Ti}_{\mathrm{x}} \mathrm{O}_{6-\delta} ; \mathrm{x}=0.70$ (a) and $\mathrm{x}=1.00$ (b). The $\mathrm{H}_{2} / \mathrm{O}_{2}$ ratio is also given.

Another important parameter of water splitting materials is the ratio of $\mathrm{H}_{2}$ produced to water supplied; values for both title samples are presented in Table S2. Due to the characteristics of the experimental setup, (see Figure S7), and to displace the equilibrium given in eq (7) towards hydrogen formation, the oxidation steps were carried out with large excess of water.

For the perovskite $\mathrm{Sr}_{2} \mathrm{CoTiO}_{6-\delta}$ the $\mathrm{H}_{2}: \mathrm{H}_{2} \mathrm{O}$ ratio diminishes along the cycles due to the decrease in the $\mathrm{H}_{2}$ production activity. This may be related to the poor cyclability displayed by this material. On the contrary, this ratio is almost constant for $\mathrm{Sr}_{2} \mathrm{CoNb}_{0.30} \mathrm{Ti}_{0.70} \mathrm{O}_{6-\delta}$ along the whole experiment, as expected from its high stability and reversible cyclability. Along the anomalous 6th cycle the reduction step did not undergo properly and thus the $\mathrm{H}_{2}$ production was lower, also reflected in the lower value of the $\mathrm{H}_{2}: \mathrm{H}_{2} \mathrm{O}$ ratio. However, after this incident the 
material recovered and maintained the activity for the rest of the cycles.

Performance retention is usually related to chemical reversibility and structural stability along cycles. To confirm these points XRD patterns of samples of both title materials were recorded at different cycling stages. Figure 5 zooms in the region of the patterns corresponding to the $(321)_{C}$ reflection for both $x=0.70$ and $x=1.00$ compounds, to show the evolution as the number of water splitting cycles increases.

Reduced $\mathrm{Sr}_{2} \mathrm{CoNb}_{0.30} \mathrm{Ti}_{0.70} \mathrm{O}_{6-\delta}$ shows a noticeably cell expansion in comparison to the pristine material (see Table S1) as the ionic size of the reduced cobalt ion is larger. ${ }^{[24]}$ The sample treated under water-saturated $\mathrm{N}_{2}$ stream for three cycles almost recovers the initial cell volume and no evident signals of phase segregation are observed (full width at half maximum, FWHM, of the $(321)_{c}$ peak of 3-cycles and pristine samples are almost identical (Table S3). After eight cycles, some structural hysteresis seems to occur since the unit cell (and Co-O distance) in this material is slightly larger than in the as-prepared oxide. Besides, broader peaks (Table S3) suggest some domain segregation, though the phases presumably present are very similar.
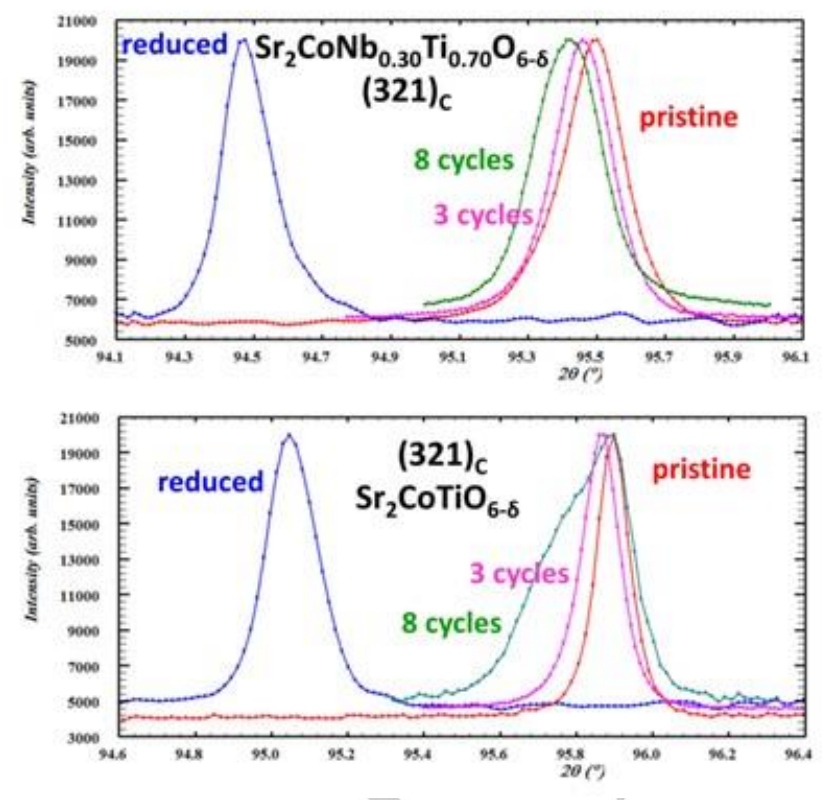

Figure 5. Reflection (321) for $\mathrm{Sr}_{2} \mathrm{CoNb}_{1-x} \mathrm{Ti}_{x} \mathrm{O}_{6-\delta}, \mathrm{x}=0.70$ (upper panel) and $\mathrm{x}=1.00$ (lower panel) compounds after reduction and different number of water splitting cycles.

Structural hysteresis and phase segregation processes are clearer for $\mathrm{Sr}_{2} \mathrm{CoTiO}_{6-\delta}$. As expected, reduction induces a noticeable cell expansion that is almost totally reverted upon treatment under wet nitrogen; no evidence of phase segregation is observed up to three cycles. However, the situation is completely different after eight cycles: phase segregation is evident since in Figure 6 two (321)c peaks are present. The two phases detected differ, most likely, in their oxygen contents, Co$O$ distances, and cobalt oxidation states. By deconvolution of the $(321)_{C}$ reflection, the phase percentages of the partially-reoxidized (Phase I) and totally-re-oxidized (Phase II) are estimated to be $62(2) \%$ and $38(2) \%$, respectively. Using the same procedure, the composition of sample $\mathrm{Sr}_{2} \mathrm{CoNb}_{0.30} \mathrm{Ti}_{0.70} \mathrm{O}_{6-\delta}$ after 8 cycles is estimated to be $40 \%$ and $60 \%$, although in this case the two phases display nearly identical cell volumes and similar oxygen contents.

Aging effect could represent a serious drawback for practical applications in long-term thermochemical cycles reactors. There exist solutions to overcome this problem: i) working at higher temperatures to improve oxygen diffusion and favor thereby total oxidation by water; ii) using nano-sized samples which will be more reactive at any temperature. Ongoing works with this latter approach are providing promising results.
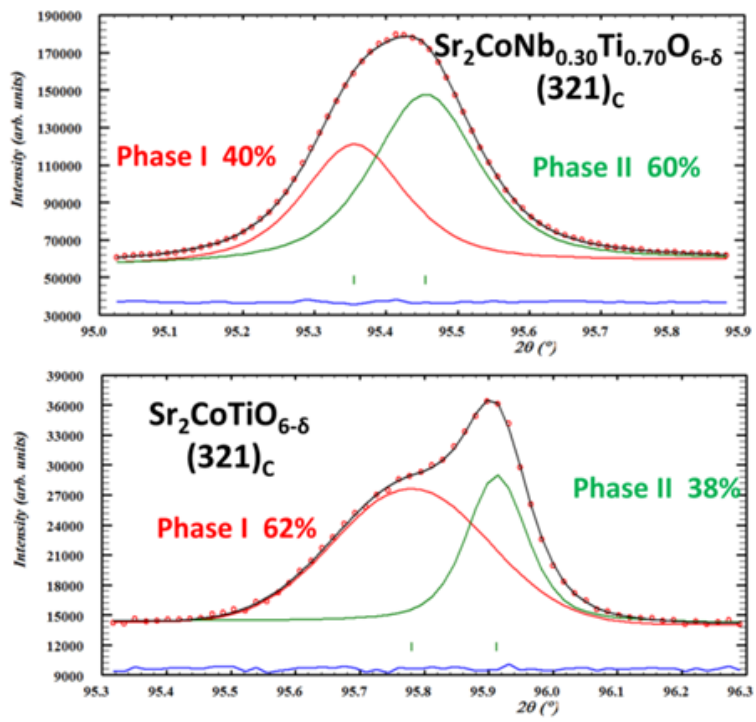

Figure 6. Deconvolution of reflection $(321)_{\mathrm{C}}$ for $\mathrm{Sr}_{2} \mathrm{CoNb}_{1-\mathrm{x}} \mathrm{Ti}_{\mathrm{x}} \mathrm{O}_{6-\bar{\delta}}, \quad \mathrm{x}=0.70$ (upper panel) and $\mathrm{x}=1.00$ (lower panel) materials after eight water splitting cycles.

\section{Evolution of cobalt oxidation state}

The oxidation state of $\mathrm{Co}$ and its local chemical environment in oxides $\mathrm{Sr}_{2} \mathrm{CoNb}_{1-\mathrm{x}} \mathrm{Ti}_{\mathrm{x}} \mathrm{O}_{6-\delta}(\mathrm{x}=0.70,1.00)$ are determined by $\mathrm{X}$ ray absorption fine structure at the cobalt K-edge (Figure 7 ) for the pristine and the reduced materials, as well as for samples after eight cycles of hydrogen production. In the as-prepared 
materials the oxidation states of cobalt, determined by the energy shift of the absorption edge, ${ }^{[29]}$ are nominally $3.0(3)$ and 3.4(3) for $x=1.00$ and $x=0.70$, respectively (Table S4). These values match the results obtained by NPD (Table S1). Reducing treatments produce Co in divalent nominal oxidation state, 1.8(3) in both materials. After eight hydrogen-production cycles Co recovers completely its initial oxidation state in both samples. This confirms that the title materials, once reduced, do react with water according to eq (7) preferentially. More information on chemical environment and coordination can be obtained by analyzing the spectral features in the XANES region on Figure 7. The white line (region of maximum absorbance just after the edge) presents a complex structure in both materials, with several resonances. Besides the chemical shift of the edge associated to the Co oxidation state, reduction induces the vanishing of the resonances in both materials, evidently related to changes in the first coordination shell of cobalt (formed by $O$ atoms). The spectra are partially recovered after re-oxidation in $\mathrm{H}_{2} \mathrm{O}$ atmosphere upon eight cycles. However, there are slight differences in the white-line intensity between pristine and cycled materials with $\mathrm{x}=0.70$; these differences are subtler for $x=1.00$. The origin of the differences in the white-line intensity without changes in the shape can be related to changes in the first-neighbors distances $(\mathrm{d}(\mathrm{Co}-\mathrm{O}))$ or to distortions in the coordination shell. ${ }^{[30]}$ The analysis of the pre-edge peak provides more insight into the origin of these distortions. Its intensity and shape give additional clues on the symmetry of the first coordination sphere of Co ions. ${ }^{[31]}$ Both pristine compounds $\mathrm{Sr}_{2} \mathrm{CoNb}_{1-\mathrm{x}} \mathrm{Ti}_{x} \mathrm{O}_{6-\delta}(\mathrm{x}=0.70,1.00)$ present intense pre-peaks as commonly observed in Co oxides, more intense for $x=1.00$ than for $x=0.70$ (Figure 7). An enhanced pre-edge peak is commonly associated to symmetry reduction of the first coordination sphere in 3d-oxides. ${ }^{[32]}$ Therefore, as-prepared $\mathrm{Sr}_{2} \mathrm{CoTiO}_{6-\delta}$ contains less symmetric $\mathrm{CoO}_{n}$ units than those present in pristine $\mathrm{Sr}_{2} \mathrm{CoNb}_{0.30} \mathrm{Ti}_{0.70} \mathrm{O}_{6-\delta}$. This is most likely due to the presence of more $\mathrm{Co}$ in tetrahedral, square pyramidal or other environments with reduced co-ordination compared to the octahedron, because of a higher concentration of anionic vacancies. This agrees with the oxygen contents determined by NPD (Table S1). After reduction, the pre-edge peaks for both compositions clearly increase, suggesting a further decrease in the coordination of cobalt; this is also observed by NPD. Cycled samples are significantly different; re-oxidation by water induces only a partial recovery of the pre-edge peak shape in the spectrum of sample with $x=1.00$ with a remnant distortion. On the contrary, for sample with $\mathrm{x}=0.70$ the peak shape and intensity are almost completely recovered after cycling; therefore structural hysteresis or phase segregation is produced in more extent for the oxide with $x=1.00$. As previously discussed, in the sample $\mathrm{Sr}_{2} \mathrm{CoTiO}_{6-\delta}$ segregation of two phases with significantly different unit cell volumes occurs after eight cycles (Figure 6 and Table S3); differences in the unit cell are associated to different $\mathrm{Co}-\mathrm{O}$ distances as a result of different $\mathrm{Co}$ oxidation states and oxygen contents. In the minority phase $\mathrm{d}(\mathrm{Co}-\mathrm{O})$ is similar to that in the pristine material (oxygen content and Co oxidation states should be similar); in contrast the predominant phase displays a larger unit cell than the as-prepared sample, corresponding to larger $\mathrm{d}(\mathrm{Co}-\mathrm{O})$ and less oxidized cobalt.

\section{Conclusion}

Samples of compositions $\mathrm{Sr}_{2} \mathrm{CoNb}_{1-x} \mathrm{Ti}_{x} \mathrm{O}_{6-\delta}(\mathrm{x}=0.70,1.00)$ prepared in air are obtained as single phase with a simple cubic perovskite structure as determined by XRD and NPD. Reduction (in $\mathrm{N}_{2}$ or $\mathrm{Ar}$ ) and oxidation (in air) of these materials are highly reversible according to TGA analyses and NPD data. Oxidation of the reduced materials by water, (wet $N_{2}$ ), involving splitting of water at a temperature as low as $700{ }^{\circ} \mathrm{C}$, produces hydrogen. Both compounds display outstanding $\mathrm{H}_{2}$ production in the first thermochemical cycle $\left(492 \mu \mathrm{molH}_{2} / \mathrm{g}_{\text {perovskite }}\right.$ for $\mathrm{x}=1.00$, and $450 \mu \mathrm{molH}_{2} / \mathrm{g}_{\text {perovskite }}$ for $\left.\mathrm{x}=0.70\right)$.
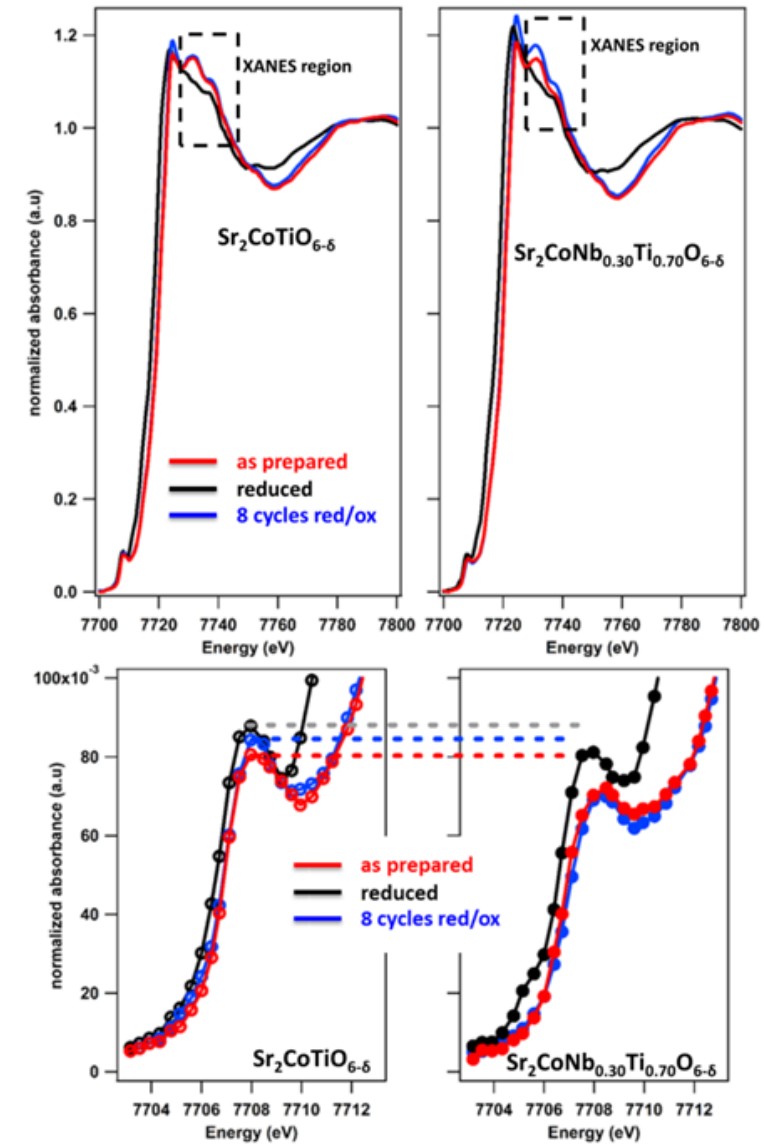

Figure 7. XAS spectra of $\mathrm{Sr}_{2} \mathrm{CoNb}_{1-\mathrm{x}} \mathrm{Ti}_{\mathrm{x}} \mathrm{O}_{6-\bar{\delta}}(\mathrm{x}=0.70,1.00)$ as-prepared, reduced and after eight red/ox cycles (upper panel). The lower panel shows details of the corresponding pre-edge peaks.

The retention of the material's ability to promote water splitting correlates well with their structural, chemical and redox reversibility upon cycling. It is also observed that along the reduction/oxidation process, Co ions reversibly change their oxidation state (as deter-mined by XAS) to compensate the release/recovering of oxygen in both compounds. 
The hydrogen production of $\mathrm{Sr}_{2} \mathrm{CoNb}_{0.30} \mathrm{Ti}_{0.70} \mathrm{O}_{6-\delta}$ remains constant upon cycling, thus retaining its out-standing performance; however, the yield of $\mathrm{Sr}_{2} \mathrm{CoTiO}_{6-\delta}$ decays continuously as the cycling process progresses, a fading of ca. $50 \%$ being observed after 8 cycles. In connection with this, two phases with different oxygen contents segregate in the early stages of cycling $\mathrm{Sr}_{2} \mathrm{CoTiO}_{6-\delta}$, whereas $\mathrm{Sr}_{2} \mathrm{CoNb}_{0.30} \mathrm{Ti}_{0.70} \mathrm{O}_{6-\delta}$ submit to the same process undergoes segregation to a much less extent into two almost identical phases.

Therefore, $\mathrm{Sr}_{2} \mathrm{CoNb}_{0.30} \mathrm{Ti}_{0.70} \mathrm{O}_{6-\delta}$ displays after 8 thermochemical cycles at $700^{\circ} \mathrm{C}$ a hydrogen production as high as 410

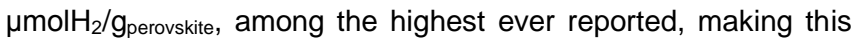
perovskite a serious candidate for thermo-solar water splitting in real devices. To ensure good long-term performance for a fullscale application, stability tests along large number of cycles are necessary. Optimization of the samples' microstructure may even improve the outstanding behavior of present perovskites, as ongoing preliminary works suggest.

\section{Experimental Section}

\section{Samples preparation and structural characterization}

The title materials have been synthesized by a modified Pechini method, previously reported by Azcondo et al. ${ }^{[22]}$ Reduced samples were obtained treating the as-prepared samples at $900{ }^{\circ} \mathrm{C}$ in a continuous flow of pure Ar for 12 hours.

X-ray diffraction (XRD) patterns were collected on a Bruker D8 highresolution diffractometer, equipped with LynxEye fast detector, using monochromatic $\mathrm{Cu}(\mathrm{Ka} 1)(\lambda=1.5406 \AA)$. Some more relevant zones of the patterns were collected at higher resolution and statistics.

Neutron powder diffraction (NPD) experiments at room temperature were performed on the high-resolution diffractometer D2B using a monochromatic beam of wavelength $1.05 \AA$. Structural refinements were carried out by the Rietveld method using the FullProf program ${ }^{[33]}$ by joint fitting of XRD and NPD data.

\section{XANES experiments}

X-ray Absorption Near-Edge Structure (XANES) experiments were carried out at the Spanish CRG BM25A SpLine beamline ${ }^{[34]}$ at the European Synchrotron (ESRF). Measurements were performed at the Co K-edge $(7.709 \mathrm{keV})$ in transmission mode using three high-precision ionization chambers with an energy resolution of $\Delta \mathrm{E} / \mathrm{E}=1.4 \times 10^{-4}$. XANES data were normalized using Athena software. ${ }^{[35]}$ The oxidation states in the compounds were determined by the Kunzl method. ${ }^{[29]}$

\section{Reversibility of the reduction-oxidation processes}

A preliminary evaluation of the redox properties of the perovskites, as well as the process reversibility, was performed by thermogravimetric experiments (TG) carried out in a TGA/DSC1 STARe System (Mettler, Toledo) up to a maximum temperature of $1000{ }^{\circ} \mathrm{C}$.

Hydrogen production
The hydrogen production (Figure S7) was evaluated on a high temperature tubular furnace working isothermally at $700 \stackrel{\circ}{\circ}$. During the reduction step the released oxygen is continuously removed with a dry nitrogen flow and carried to a paramagnetic gas analyser. For the second step, oxidation by water, the furnace is fed with a nitrogen stream saturated with water at $80 \stackrel{\circ}{\circ}$. The $\mathrm{H}_{2}$ production was determined after drying the stream by thermal conductivity.

\section{Acknowledgements}

We thank Agencia Estatal de Investigación(AEI)/Fondo Europeo de Desarrollo Regional (FEDER/UE) for funding the project MAT2016-78632-C4-1-R. We acknowledge CSIC, ILL and ESRF for financial support and facilitate the access to the BM25SpLine line at ESRF and D2B diffractometer at ILL. The authors also thank to "Comunidad de Madrid" and European Structural Funds for their financial support to ALCCONES (S2013/MAE2985) and MATERYENER3-CM (S2013/MIT-2753) projects.

Keywords: hydrogen generation, water splitting, thermo-solar, perovskite, thermochemical cycle.

\section{References}

[1] B. Dudley, in BP Statistical Review of World Energy (Ed.: B. p.l.c.), British Petroleum, London, 2017.

[2] T. Trainer, Energy Policy 2017, 110, 386-393.

[3] aA. Rakesh, M. D. S., AlChE Journal 2010, 56, 2762-2768; bL. G. Paterno, in Nanoscience and its Applications (Eds.: A. L. Da Róz, M. Ferreira, F. de Lima Leite, O. N. Oliveira), William Andrew Publishing, 2017, pp. 1-33.

[4] C. Perkins, A. W. Weimer, International Journal of Hydrogen Energy 2004, 29, 1587-1599.

[5] L. Xiao, S.-Y. Wu, Y.-R. Li, Renewable Energy 2012, 41, 1-12.

[6] M. Roeb, N. Monnerie, A. Houaijia, D. Thomey, C. Sattler, Solar Thermal Water Splitting, 2013.

[7] P. Charvin, A. Stéphane, L. Florent, F. Gilles, Energy Conversion and Management 2008, 49, 1547-1556.

[8] M. Orfila, M. Linares, R. Molina, J. Angel Botas, J. Marugan, R. Sanz, International Journal of Hydrogen Energy 2017, 42, 13532 13543.

[9] T. Abbasi, S. A. Abbasi, Renewable \& Sustainable Energy Reviews 2011, 15, 3034-3040.

[10] D. Yadav, R. Banerjee, Renewable \& Sustainable Energy Reviews 2016, 54, 497-532.

[11] J. D. Holladay, J. Hu, D. L. King, Y. Wang, Catalysis Today 2009, 139, 244-260.

[12] aC. L. Muhich, B. D. Ehrhart, I. Al-Shankiti, B. J. Ward, C. B. Musgrave, A. W. Weimer, Wiley Interdisciplinary Reviews-Energy and Environment 2016, 5, 261-287; bA. Haeussler, S. Abanades, J. Jouannaux, A. Julbe, Catalysts 2018, 8, 611; cA. A. Emery, J. E. Saal, S. Kirklin, V. I. Hegde, C. Wolverton, Chemistry of Materials 2016, 28, 5621-5634.

[13] A. H. McDaniel, A. Ambrosini, E. N. Coker, J. E. Miller, W. C. Chueh, R. O'Hayre, J. Tong, in Proceedings of the Solarpaces 2013 International Conference, Vol. 49 (Ed.: R. Pitchumani), 2014 pp. 2009-2018.

[14] aC.-K. Yang, Y. Yamazaki, A. Aydin, S. M. Haile, Journal of Materials Chemistry A 2014, 2, 13612-13623; bJ. R. Scheffe, D. Weibel, A. Steinfed, Energy \& Fuels 2013, 27, 4250-4257; cM. Orfila, M. Linares, R. Molina, J. Angel Botas, R. Sanz, J. Marugan, International Journal of Hydrogen Energy 2016, 41, 19329-19338; dA. H. McDaniel, E. C. Miller, D. Arifin, A. Ambrosini, E. N. Coker, R. O'Hayre, W. C. Chueh, J. Tong, Energy \& Environmental Science 2013, 6, 2424-2428; eA. Demont, S. Abanades, E. Beche, Journal of Physical Chemistry C 2014, 118, 12682-12692. I. S. Metcalfe, B. Ray, C. Dejoie, W. Hu, C. de Leeuwe, C. Dueso, F. R. García-García, C.-M. Mak, E. I. Papaioannou, C. R. Thompson, J. S. O. Evans, Nature Chemistry 2019.

F. R. García-García, C.-M. Mak, E. I. Papaioannou, C. R.
Thompson, J. S. O. Evans, Nature Chemistry 2019.


R. H. Mitchell, Perovskite: Modern and Ancient, Ontario (Canada), 2002.

aA. E. York, T. Xiao, M. H. Green, Topics in Catalysis 2003, 22, 345-358; bS. Tao, J. T. S. Irvine, Nat Mater 2003, 2, 320-323; cZ. Shao, S. M. Haile, Nature 2004, 431, 170-173; dD. Chen, C. Chen, Z. M. Baiyee, Z. Shao, F. Ciucci, Chemical Reviews 2015, 115, 9869-9921.

[18] S. B. Adler, Chemical Reviews 2004, 104, 4791-4844.

[19] J. R. Petrie, H. Jeen, S. C. Barron, T. L. Meyer, H. N. Lee, Journal of the American Chemical Society 2016, 138, 7252-7255.

[20] aM. Teresa Azcondo, M. Yuste, J. Carlos Perez-Flores, D. MunozGil, S. Garcia-Martin, A. Munoz-Noval, I. P. Orench, F. GarciaAlvarado, U. Amador, Chemsuschem 2017, 10, 2978-2989; bA. J. Jennings, S. J. Skinner, Solid State lonics 2002, 152, 663-667; cG. Amow, J. Au, I. Davidson, Solid State Ionics 2006, 177, 18371841; dM. Al Daroukh, V. V. Vashook, H. Ullmann, F. Tietz, I. Arual Raj, Solid State Ionics 2003, 158, 141-150. [21] aM. Kubicek, A. H. Bork, J. L. M. Rupp, Journal of Materials
Chemistry A 2017, 5, 11983-12000; bB. Bulfin, J. Vieten, C. Agrafiotis, M. Roeb, C. Sattler, Journal of Materials Chemistry A 2017, 5, 18951-18966.

[22] M. Teresa Azcondo, J. Romero de Paz, K. Boulahya, C. Ritter, F. Garcia-Alvarado, U. Amador, Dalton Transactions 2015, 44, 3801 . 3810.

aM. Yuste, Perez-Flores, J.C., Romero de Paz, J., Azcondo,M.T., Garcia-Alvarado, F., Amador, U., Dalton Trans. 2011, 40, 7908; bA. Gómez-Pérez, Yuste, M.,Pérez-Flores, J.C.,Ritter, C., Azcondo,

M.T., Canales-Vázquez, J., Gálvez-Sánchez, M.,Boulahya, K.,García-Alvarado, F., Amador, U., Journal of Power Sources 2013, 227, 309-317.

R. D. Shannon, Acta Crystallographica Section A 1976, 32, 751 767.

C. Agrafiotis, M. Roeb, C. Sattler, Renewable \& Sustainable Energy Reviews 2015, 42, 254-285.

W. C. Chueh, C. Falter, M. Abbott, D. Scipio, P. Furler, S. M. Haile, A. Steinfeld, Science 2010, 330, 1797-1801.

R. J. Panlener, R. N. Blumenthal, J. E. Garnier, Journal of Physics and Chemistry of Solids 1975, 36, 1213-1222.

J. R. Scheffe, J. Li, A. W. Weimer, International Journal of Hydrogen Energy 2010, 35, 3333-3340.

V. Kunzl, Collect. Trav. Chim. Techecolovaquie 1932, 4.

J. J. Rehr, R. C. Albers, Reviews of Modern Physics 2000, 72 ,

621-654.
T. Yamamoto, X-Ray Spectrometry 2008, 37, 572-584.

A. Corrias, G. Ennas, G. Mountjoy, G. Paschina, Physical Chemistry Chemical Physics 2000, 2, 1045-1050.

J. Rodríguez-Carvajal, Physica B: Condensed Matter 1993, 192, 55-69. The program and manual can be found at

http://www.ill.eu/sites/fullprof/.

B. Ravel, M. Newville, Journal of Synchrotron Radiation 2005, 12 , 537-541.

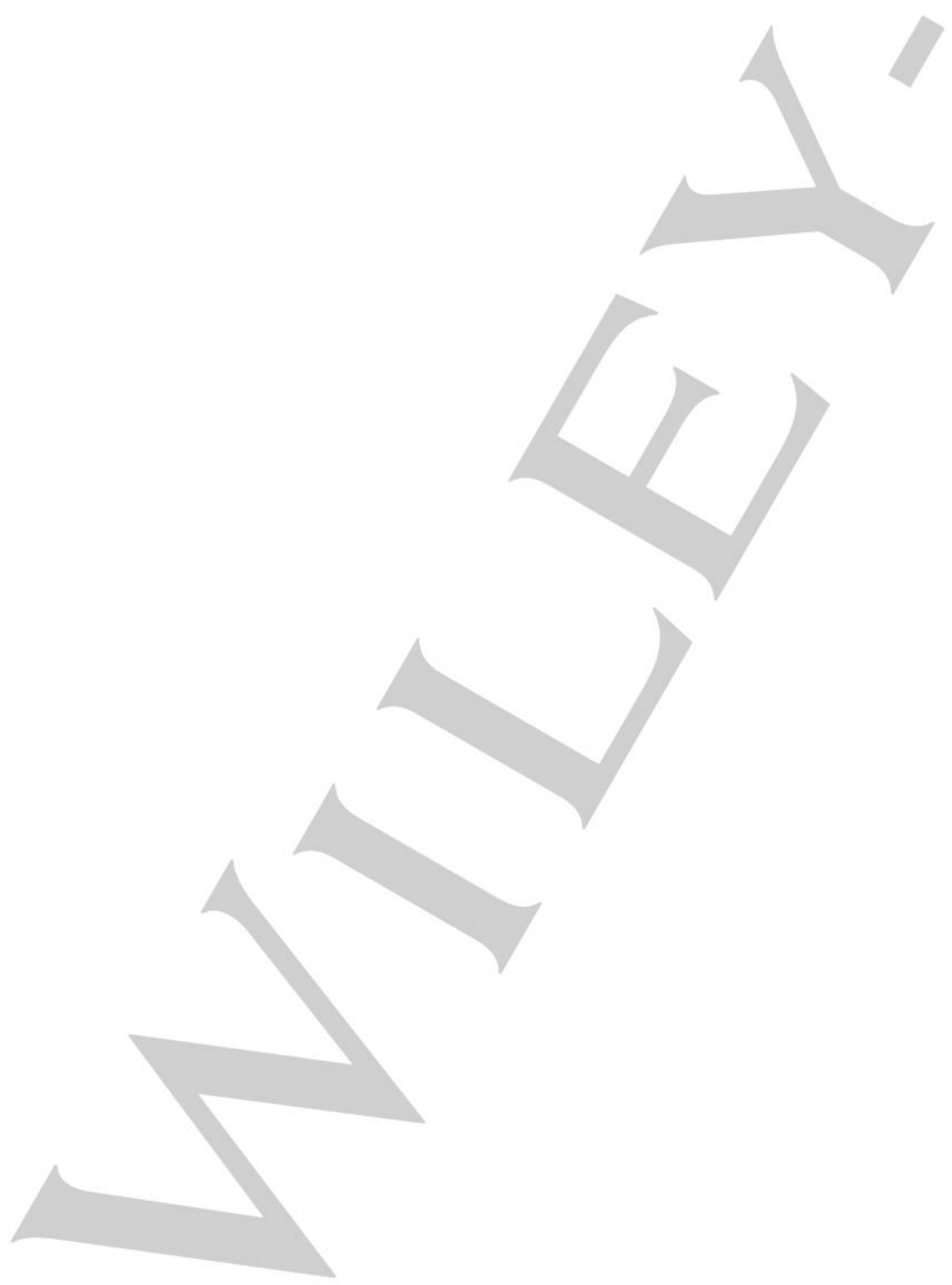


Entry for the Table of Contents (Please choose one layout)

Layout 1:

\section{RESEARCH ARTICLE}

Clean hydrogen can be produced through water splitting at moderate temperature, $700^{\circ} \mathrm{C}$, by two-step reversible thermochemical cycles based on perovskite oxides

$\mathrm{Sr}_{2} \mathrm{CoNb}_{1-\mathrm{x}} \mathrm{Ti}_{\mathrm{x}} \mathrm{O}_{6-\delta}(\mathrm{x}=1,0.7)$.

These compounds show outstanding hydrogen yield making them potentially useful for real applications.

Keywords: Hydrogen, water splitting, perovskite phases, thermochemical cycle, solar fuel

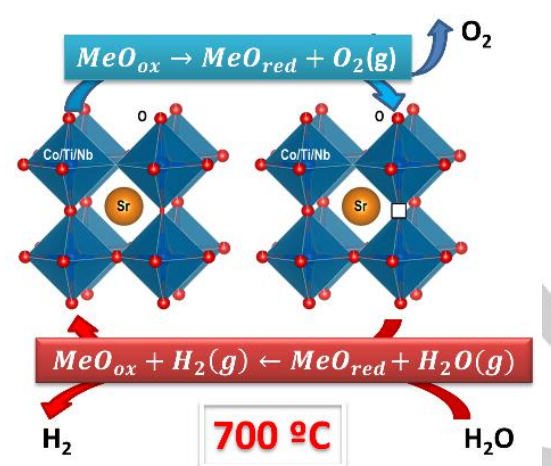

M. Teresa Azcondo, * María Orfila, ${ }^{*}$ Javier Marugán, Raúl Sanz, Alvaro Muñoz-Noval, Eduardo Salas-Colera, Clemens Ritter, Flaviano GarcíaAlvarado, Ulises Amador

Page No. - Page No.

Novel perovskite materials for thermal water splitting at moderate temperature 